J. Lake Sci. (湖泊科学) , 2011, 23(6): 821-827

http: //www. jlakes. org. E-mail : jlakes@niglas.ac.cn

(C) 2011 by Journal of Lake Sciences

\title{
基于营养盐的中国湖泊生态分区框架与指标体系初探
}

\author{
张德禄 ${ }^{1,2}$, 刘永定 $^{1}$, 胡春香 $^{1 * *}$ \\ (1: 中国科学院水生生物研究所,武汉 430072) \\ $(2$ :武汉理工大学,武汉 430070)
}

摘 要: 湖泊营养盐水生态分区是湖泊营养盐基准和富营养化控制标准制定的基础, 是对湖泊富营养化进行综合评估、 预防、控制和管理的科学基础和重要手段. 本文通过对生态分区、水生态分区概念内涵的辨析,生态分区划分依据的探 讨, 及营养盐生态效应在空间表征、驱动因子、响应模式上的分异分析,剖析了基于营养盐的湖泊水生态分区概念内涵, 提出了中国湖泊实行 “分区、分类、分级” 的三级划分框架; 指出以气候带、地形地貌、流域水系等地带相似性为分区的依 据, 以区域内地形地貌、土壤营养吸附量、土地利用格局、湖盆形态 (水深、面积、岸线发育)、水文特点 (交换周期、水位变 动、矿化度) 等方面的差异为主要分类指标, 以营养盐浓度、初级生产者 (浮游藻类、周丛藻类和水生维管植物) 生物量、单 位营养盐浓度下的初级生产者生物量、初级生产者优势种群类型等为分级指标的划分依据; 以发生学、等级性、相似性、 分异性、完整性、综合性等为分区原则,初步构建了湖泊水生态分区的指标体系,为中国基于营养盐的湖泊水生态分区做 了奠基性的准备工作.

关键词: 湖泊;富营养化;营养盐;水生态分区

\section{Ecoregional frame and indices system based on nutrients in Chinese lakes}

\author{
ZHANG Delu ${ }^{1,2}$, LIU Yongding ${ }^{1} \&$ HU Chunxiang ${ }^{1}$ \\ ( 1 : Institute of Hydrobiology, Chinese Academy of Sciences, Wuhan 430072, P. R. China) \\ (2:Department of Biology, Wuhan University of Technology, Wuhan 430070, P. R. China)
}

\begin{abstract}
The ecoregionalization based on lacustrine nutrients is the basis of nutrient benchmark and trophication control criteria of lakes, and is also the scientific basis and magnitude pathway of compositive evaluation, prevention, control and management. In this paper, after analyzing the concepts on ecoregion, hydroecoregion, and discussion on the base of classification, the lacustrine response to nutrients in geographic sections, driving factors and models, we proposed a Chinese hydroecoregional frame based on regionalization, classification and phase. By analyzing the environmental factors that influencing trophic status, we determined the criterions for lake regionalization, including by climate zone, topography and water system; by topography, soil nutrients, land use, shape of lake basin (water depth, surface area, development of lake shore) and hydrologic characteristics (residence time, water level, degree of mineralization); by nutrient content (nitrogen, phosphorus et al), total primary productivity (biomass of phytoplankton, attached alga and aquatic macrophyte), and by dominant plant types (phytoplankton and macrophyte). We primarily constructed indices system of ecoregionalization for Chinese lakes and this work lays a basis of lake ecoregionalization based on nutrients in China.
\end{abstract}

Keywords: Lake; eutrophication; nutrient; aquatic ecoregionalization

湖泊是人类赖以生存的重要水资源, 它不仅是农业、养殖业和人们生活用水的主要来源, 同时还具有调 节气候、蓄纳洪水、维持生物多样性等重要功能. 但自 1950s 以来, 随着中国经济的快速发展、人口的增长、工 业化和城市化进程的加速, 进入湖泊的氮磷量大大增加, 使水体富营养化明显加剧. 而富营养化不仅使水体

* 国家水体污染控制与治理科技重大专项项目 (2009ZX07106-001-003)资助. $2011-01-19$ 收稿;2011-07-19 收修改稿. 张德禄, 男,1963 年生, 博士; E-mail: deluzh@163. com.

** 通讯作者;E-mail:cxhu@ihb. ac. cn. 
应有的功能丧失,引起的环境问题还制约着社会经济的可持续发展.

湖泊富营养化的根本原因是营养盐浓度过高或营养盐输人量过大, 有效削减和控制入湖营养盐的量, 是控制湖泊富营养化、修复湖泊水生态系统的关键. 但中国地域辽阔, 湖泊分布广泛、成因复杂、类型多样, 各湖的水文、地质及周边土壤、地形、土地利用等自然条件的千差万别, 不同地区的社会经济和人为干扰程 度也存在明显差异, 这样不仅不同自然条件、不同来源湖泊中的营养盐本底值明显不同, 即使同等自然条件 下的湖泊营养盐水平也明显不同, 甚至同等营养盐水平下富营养化的表征也完全不同. 为提升中国湖泊富 营养化控制与管理水平,科学指导湖泊富营养化综合防治工作, 国家需要尽快制定不同区域湖泊富营养化 控制标准, 而湖泊营养盐分区是湖泊营养盐基准和富营养化控制标准制定的基础和前提. 因此, 对全国的湖 泊进行生态分区, 是遵从生态规律, 切实有效地缓解和解决中国富营养化现状的务实之举.

国际上, 关于湖库的水生态分区, 美国联邦环保局 (USEPA) 早在 1970s 末就已经开始了. 他们从区划体 系的研究方法人手, 根据地貌、土壤、植被和土地利用四个要素提出了美国的区划方案 ${ }^{[1]}$. 而这一方案不仅 得到美国管理部门的普遍认可, 同时也得到了世界许多国家和地区的关注和追随 ${ }^{[2-6]}$, 而且以水生态区的生 态状况为参考确定保护和恢复的目标已成为全球淡水生态系统保护和治理的基本原则 ${ }^{[7]}$.

中国从 $1950 \mathrm{~s}$ 就开始了水体的区划研究, 有人根据地理位置把湖泊划分为五大湖泊区 ${ }^{[8]}$; 窦鸿身等就中 国湖泊的分类原则和级别划分作了分析 ${ }^{[9]}$; 也有人根据鱼的分布特征做出内陆渔业区划 ${ }^{[10]}$ 和淡水鱼类分布 区划 ${ }^{[11]}$ 等. 但这些区划都是自然地理属性上的划分, 不是真正意义上的水生态区划. 2005 年尹民等为满足 生态水量标准制定的需求, 在以往水文区划的基础上, 提出了中国的河流生态水文区划方案 ${ }^{[12]}$; 2005 年富 国以三峡水库为例对湖泊富营养化分级的指标体系进行了分析 ${ }^{[13]} ; 2007$ 年孟伟等就美国水生态分区方法 在中国的应用前景进行了探析 ${ }^{[7]}$, 并对辽河流域水生态分区进行了研究 ${ }^{[14]} ; 2008$ 年杨爱民等将生态分区、 水文分区、水资源分区、综合自然分区综合在一起提出了中国的生态水文分区 ${ }^{[15]} ; 2010$ 年孙小银和周启星 通过行政分区、水文分区、水环境功能分区、水生态分区优缺点的对比分析,提出了中国包括河流、溪流和湖 泊在内的整个淡水资源的水生态分区框架 ${ }^{[16]}$, 但以前的分区, 即使是生态分区, 也只是在分区中增加了部分 生态学指标, 没有提出分区的依据, 也没有指出需要控制的生态现象或目的, 可操作性差. 再者, 基于营养盐 的生态分区研究仍是空白.

\section{1 生态分区的概念}

“生态区” ( ecoregion) 一词是加拿大人 Drie Loucks 首次提出的, Crowley、Bailey、Omernik 等是在此概念 下分别绘制了加拿大、美国、世界大陆和海洋等系列生态区分布图 ${ }^{[17]}$. 综观他们划分的特点, 地理学家强调 更多的是地点、尺度、自然和社会的基础; 生态学家则更注重能量流动和物质循环的环境过程. 在生态学家 的眼中, 真正意义上的生态分区, 是从生态系统的整体出发, 把空间结构格局与生态功能和生态过程结合起 来, 侧重于区域生态系统的结构和功能的一致性 ${ }^{[18]}$, 并将生态分区与区域开发及生产规划更加密切联系起 来的区划方法 ${ }^{[19-20]}$. 虽然它与比邻的区域相比是异质的, 但在过渡带它既是空间镶嵌体, 又是功能单元 ${ }^{[21]}$, 而且,针对不同的目的和不同的使用者, 分区的结果是不相同的 ${ }^{[22-23]}$.

目前, 生态分区虽然已被广泛应用于很多国家的资源保护和环境管理评价之中, 但能够被普遍接受的 基于生态分区的理论基础还是空缺的 ${ }^{[20]}$. 而且生态系统的异质性由于系统边界与稳定性、人类与生态区域 一致性、系统区域的模式与尺度及系统中等级空间关系等方面的争议而较难操作 ${ }^{[20]}$.

关于水生态分区 (Hydroecoregions, HERs) 的概念, Omernik 定义为具有相对同质的淡水生态系统或生 物体及其与环境相互关系的地域单元 ${ }^{[1]}$. 但这些单元的区域特征是由多种要素决定的, 而且这些要素在各 个区域发挥的作用还不尽相同. 所以, 水生态分区的实质是在一定尺度下为不同目的而进行的水体分类方 法, 它选择的分类指标要能够体现各个单元的匀质性、异质性和完整性. 孟伟等提出: 水生态分区是以流域 水生态系统及其影响因素为研究对象, 应用河流生态学中的格局与尺度等原理与方法, 对水体及其周围陆 地所进行的区域划分方法 ${ }^{[24]}$. 但在解决具体问题, 面对不同的分区目标时, 生态系统的边界应该是多层次、 多尺度的, 不应仅局限于一个层面 ${ }^{[17]}$. 


\section{2 生态分区划分的依据}

生态分区研究的目标是为了阐明区域生态系统的等级性,并把这种均质的等级性和异质的地域镶嵌格 局以不同等级的生态系统较为清晰地表达出来, 以便采用不同的管理标准和实施不同的修复或治理措 施 ${ }^{[19,23]}$. 分区划分的依据主要指区域单元的一致性, 它随系统等级的不同而不同,这种不同可能是指标内涵 上的, 也可能是指标数值上的. 它主要指自然生态系统结构与功能特征的相似性 ${ }^{[25]}$, 可能是由多个重复的、 具有多种等级水平的景观格局组成的 ${ }^{[26]}$.

关于生态分区划分的依据,有人认为生物多样性是生态系统的核心 ${ }^{[27]}$,生态分区应该建立在能够满足 不同种类生存需求的生境基础之上 ${ }^{[28]}$. 但物种多样性的确定需要很多个学科的专业人员熟练操作, 人为影 响因素较大, 更重要的是生物多样性与生态系统稳定性间的关系尚无定论 ${ }^{[29]}$, 另外水生生物的多样性与营 养盐之间不成线性关系 ${ }^{[30]}$, 因此很少被应用. 目前, 比较认同的是, 在地球表面基本的生态系统功能单元中, 绿色植物是系统初级能量的唯一来源, 是系统中最核心的成分, 因而, 植物群落生产力的高低常被用来反映 生态系统的功率 ${ }^{[31-32]}$, 不少生态分区也以植物群落生产力的高低作为生态一致性或区域生产潜力的衡量 标准 ${ }^{[19,33]}$.

\section{3 营养盐的生态学效应}

虽然营养盐的过量输人是导致湖泊富营养化的根本原因,但富营养化的表征随环境条件的不同而不 同 ${ }^{[34]}$, 大致上有藻型和草型两大类. 藻型富营养化主要表现为浮游藻类和着生藻类的过度繁殖, 而且有蓝 藻、硅藻、甲藻、裸藻、隐藻等多种类型, 其中蓝藻又可细分为球形藻和丝状藻, 或有毒藻和无毒藻. 草型富营 养化表现为挺水植物、漂浮植物或沉水植物的过度繁殖. 因此, 湖泊的富营养化类型和程度难以用单一指标 (如叶绿素浓度) 统一定量表达.

尽管氮、磷等生源要素是富营养化的重要原因,但营养盐转化为生物质的效率仍然受到多种因素的制 约,富营养化的驱动因子也随条件的变化而变化. 在地带尺度上,它受光、热、水等气候因素的影响; 在区域 尺度上,受地貌、土壤、植被、水文、土地利用、人为干扰等因素的影响; 在湖泊尺度上,还受湖泊成因、形态、 水动力等因素的影响. 因此,气候带、地形地貌、植被类型、土壤营养、土地利用、人为干扰等方面的区域特征 是反映湖泊流域水生态系统与周围陆地生态系统相关关系的关键因素.

另外, 富营养化对营养和非营养驱动因子的响应模式也存在空间差异, 如云贵高原湖群区、东部平原湖群 区、干旱内陆湖群区、青藏高原湖群区、华北湖群区等区域间, 浮游植物叶绿素浓度和维管植物生物量与水体 营养和非营养因素间的关系不是同类模式,即使在同一湖群区的同一模式下,定量关系亦有所不同 ${ }^{[35-36]}$.

\section{4 基于营养盐的湖泊水生态分区}

\section{1 基于营养盐的湖泊水生态分区内涵}

由于营养盐明显不同的生态学效应, 笔者认为, 基于营养盐的湖泊水生态分区, 应该是通过掌握水生态 系统单元中水生生物生产力随环境营养压力变化的规律, 根据初级生产者(包括浮游藻类、周丛藻类和水生 维管植物) 生产力总和, 或营养盐生物学效应 (进人食物链的转化率) 的相似性而划分的自然水生态系统单 元. 该单元不仅是具有相似生态系统的湖泊水域,还应包括分水线以内的广大的陆地集水区. 其核心在于浮 游的、底栖的藻类植物和水生维管植物生产力总和及其它们受环境因素影响所发生的能流、物流和信息流 功能体. 与陆地生态系统的生物地理群落相比较, 湖泊生态系统本身就是个匀质的“群丛”. 它们镶嵌在复杂 辽阔的陆地区域生态系统范围内, 受多因子的多层次影响, 呈多阶段发展. 但就湖泊之间相比较, 它们又不 是匀质的. 随富营养化程度或季节的变化, 水华发生的频率和强度明显不同, 水生植被的生物量不同, 优势 藻类或优势群丛也不相同.

\section{2 基于营养盐的湖泊水生态分区框架及划分依据}

在地球上,宏观气候带几乎决定着自然生态系统的整体格局,控制着初级生产者所需的太阳能和湿 度 ${ }^{[37]}$. 而且, 气候带和地形地貌共同影响着土壤的构成,进一步影响着植被类型的分布范围, 而不同植被类 
型的分布又决定着其他生物的分布格局. 因此,地球生物的活动虽然有一定的自主性,但地带性因素对它们 总的分布格局仍起主导作用 ${ }^{[38-39]}$, 水生生物在大尺度上的分布也主要受气候和地形等地带性因素的影 响 ${ }^{[38,40-41]}$. 所以, 根据中国湖泊的分布特点和不同地域湖泊在富营养化效应方面的明显差异, 笔者认为从 “分区、分类、分级”的三级框架进行划分比较合理可行.

首先是“分区” : 即地带级的生态系统分区, 可依据气候带、地形地貌、流域水系等方面的差异来划分, 它 主要反映的是由纬度地带、大气环流及垂直地带共同形成的生态系统大格局. 其中, 气候带和地形地貌主要 反映的是由气候引起的水、气、热条件;水系反映大致的空间范围.

其次是 “分类”, 可在大环境相似的区域中, 依据地形地貌、土壤氮、磷吸附量 (营养盐本底)、土地利用、 湖泊水交换周期、水深、水面积、湖泊系数等水文特点进行划分, 因为土壤氮、磷吸附量直接代表着周缘土壤 本底中的营养负荷量; 土地利用格局可反映集水区可能带人水体中的营养盐量, 湖泊本身的水文属性与水 华发生有非常直接的关系 ${ }^{[42]}$, 水深和面积很大程度上反映的是湖泊的体量, 对外源营养盐的稀释和缓冲能 力, 大湖的营养盐再循环效率较小湖泊高, 外源营养在浅水性湖泊转化为生物量的效率也要高 ${ }^{[43]}$; 交换周期 反映的是营养盐的稀释和去除能力, 时间短, 附着藻类可能多些, 浮游藻类会少些 ${ }^{[1]}$; 湖泊系数能够反映湖 泊的形状、大小及其水体随风力和湖流的运动能力 ${ }^{[42,44]}$, 而运动速度快的水体中浮游植物的生长要慢得多.

最后是 “分级” : 可以在同一区域同一类型湖泊间, 依据同一季节下营养盐浓度、其他非营养因素及初级 生产者的生物量、优势浮游植物群落类型 (非固氮蓝藻、固氮蓝藻、绿藻、硅藻、甲藻、隐藻等) ${ }^{[4546]}$ 、优势水生 植物群丛类型 (挺水植物、沉水植物、浮叶植物、漂浮植物等 $)^{[47]}$ 进行生态划分, 它所反映的是在相似营养条 件下富营养化在表征方面的差异, 体现着富营养化的程度. 如, 透明度是以美国为代表的一些国家规定深水 性湖泊中反映浮游植物生物量的重要因素, 但在我国大多数浅水性湖泊中并不明显; 而总氮 ( TN)、总磷 ( TP)、 $\mathrm{Si}$ 等是所有湖泊光合自养生物生长的原因变量 ${ }^{[48]}$, 它们与浮游植物和维管植物生物量间存在明显的 线性关系 ${ }^{[34,49-53]}$, 尤其是浮游植物和水生维管植物与氮、磷浓度的关系最为密切 ${ }^{[52-55]}$; 叶绿素 a ( Chl.a) 长期 以来一直是反映藻类生物量的重要指标 ${ }^{[56]}$, 单位营养盐下的 Chl. a 浓度还可反映营养盐进人食物链的速 率 ${ }^{[57]}$, 优势浮游植物类型和优势维管植物类型常与富营养化程度密切相关 ${ }^{[46]} ; \mathrm{GPP} / \mathrm{R}$ 可大致反映生态系统 中碳营养的利用格局,体现富营养的程度 ${ }^{[48]}$.

\section{5 基于营养盐的生态分区原则}

基于营养盐的湖泊分区是为了控制湖泊富营养化而进行的, 它既不同于地理分区,也不等同于理想的 湖泊生态分区. 而要做到这点, 必须坚持以下原则:

\section{1 发生学原则}

湖泊是相对独立的历史自然体, 同等营养盐浓度所导致的效应与其自然地理条件和发生发展的历史紧 密相连, 因此, 分区时首先要遵循的原则是: 同一区域单元内的湖泊, 在初级生产者生物量形成所必需的气 候、光热等资源方面要有较高的相似性; 在分类时, 同一类型湖泊的演化 (历) 史和目前的水文特性应该有较 高的相似性.

\section{2 等级性原则}

水生态系统是极其复杂的, 各要素所起的作用是不同的, 因此, 在分区过程中, 应强调和突出主导性因 素的作用, 不同级别单元间应遵从上级制约下级,下级服从上级的原则. 在我们的思路下, 围绕光热资源的 地带性分区指标是最高级指标, 区域内的分类指标为服从于分区指标的中级指标; 与光热资源相比, 区域内 的营养本底作为中级指标比较适宜; 将营养盐浓度与富营养化程度直接联系的分级指标适合于做服从于分 类指标的最低级指标, 只能根据同一区域同一类型的湖泊而论.

\section{3 单元内一致性原则}

在同一区域内的湖泊中,光热资源、水系等要尽可能一致; 在同一区域的同一类型湖泊中,水文状况、湖 泊系数、流域营养盐本底、土地利用格局等方面要尽可能一致; 在同一区域同一类型同一富营养程度的水体 中,相似的营养盐浓度范围下应该有相似的初级生产者生物量和优势生物类型.

\section{4 单元间的分异性原则}

分异性是复杂生态系统中最普遍的规律, 与生态系统单元内相对的一致性原则相对应, 不同区域内的 
湖泊在光热资源和水系方面应尽可能不同; 不同类型湖泊间 (尤其在同一区域内) 的水文、湖泊特点、流域营 养盐本底、土地利用格局等方面尽可能不同; 在富营养程度不同的水体中 (尤其同一区域的同一类型湖泊 间),不同营养盐浓度范围下的初级生产者生物量和优势生物类型应尽可能不同.

\section{5 单元内系统结构功能的完整性原则}

自然界中任何生态系统都不是孤立存在的,它们在地理位置上相互镶嵌, 相互包含. 因此, 在进行边界 划分时, 确保单元内主要的生产者、消费者、分解者生活史各阶段的完整性尤为重要. 从可操作角度讲, 主要 是要遵循自然分水线原则, 使本区域的营养盐不要或很少直接外流到其它区域. 边界的确定一般以重要因 素的空间特点和关系度作评判, 对以上方法不能解决的重迭区, 再根据调查数据并结合专家经验来确定.

\section{6 综合性原则}

生态系统是包括生命有机体和非生命环境基质的综合体,生命过程受环境条件的影响,而生命活动反 过来也影响改变着环境条件. 因此,水生态分区既要考虑生命有机体, 尤其是初级生产者的特点, 也要参考 环境要素的影响,如光热资源、流域本底、土地利用、营养盐浓度等,因为它既是自然的、地理的,也是生物 的、化学的.

\section{6 中国基于营养盐生态分区的指标体系}

指标的篮选是实现生态分区原则的关键步骤, 指标体系的构建是完成生态区划方案的前提, 但选取的 指标既要体现生态系统的本质,又不要使指标体系过于繁杂而难于操作.

根据现有的认识, I 级指标是最高级的分区指标, II 级指标是必需服从 I 级指标的分类指标, III 级指标 是同时服从 I 级和 II 级指标的分级指标. 中国分区的初步指标如下:

I 级指标有:气候带 ( 寒温带、中温带、暖温带、亚热带、热带、高原气候区, 湿润带、半湿润带、半干旱带、 干旱带), 地貌 (平原、高原、山地), 流域指标 (水系), 据此可划分出 8 个区域 (具体数据资料将在后期 发表).

II 级指标为:在 I 级分区指标基础上,增加湖盆形态 (水深、面积、岸线发育),水文特点(交换周期、水位 变动、矿化度), 地形地貌 (高程、坡度、坡长), 土壤性质 (土壤质地、土壤含磷量、土壤含氮量), 流域景观格 局 (林地、草地、水域、建设用地、耕地、未利用地等) 等指标, 而且, 在不同区域内, 以上各指标有不同的权重.

III 级指标有: 在 I、II 级指标基础上,增加 TN、TP、Si、Chl.a、Chl.a/TP、维管植被盖度、维管植被盖度/TN、 维管植被盖度/TP、优势藻类型/优势植被类型、GPP/R 等指标, 最终得到在不同区域内不同类型湖泊中, 初 级生产者的生物量和优势生物类型随水环境中营养盐浓度对应变化的数值范围. 在此基础上, 分区分级选 择参照湖泊进行实验验证,结合统计学方法可得到各区各类湖泊的营养盐基准.

\section{7 结论}

针对我国湖泊分布广泛、类型多样、成因复杂、营养盐生态效应空间分异明显的事实,本着切实可行、科 学有效的原则,认为“分区、分类、分级”的三级区划框架适合于中国湖泊的基于营养盐的生态分区.

“分区、分类、分级”的三级区划为:在全面调查研究中国湖泊营养盐效应空间分异规律、驱动因子和富 营养化表征特点的基础上,先依据空间分异的地带性因素对湖泊进行分区,然后依据湖泊本身水文属性响 应富营养化的特点对它们进行分类,最后,针对各区各类湖泊对营养盐的表征特征进行分级. 由于各影响因 素在不同层次的作用程度显著不同,需要针对各区、各类、各级的具体情况确定其作用大小. 但划分的依据 为同区、同类、同级湖泊间初级生产力或营养盐的转化利用率基本相似.

分区的指标可以从气候带 (寒温带、中温带、暖温带、亚热带、热带、高原气候区, 湿润带、半湿润带、半干 旱带、干旱带)、地貌(平原、高原、山地) 和流域指标 (水系) 等地带相似性方面划分; 分类的指标, 在遵从分 区指标的前提条件下, 根据同区内湖盆形态 (水深、面积、岸线发育)、水文特点 (交换周期、水位变动、矿化 度)、地形地貌(高程、坡度、坡长)、土壤性质(土壤质地、土壤含磷量、土壤含氮量)、流域景观格局 (林地、草 地、水域、建设用地、耕地、未利用地等)等进行划分; 分级的指标,在遵从分区、分类指标的前提条件下，从湖 泊 TN、TP、Si、Chl.a、Chl.a/TP、维管植被盖度、优势藻类型/优势植被类型、GPP/R 等方面考虑. 
分区的原则包括湖泊的发生学原则、划分指标间的等级性、生态单元内的相似性、单元间的分异性、单 元结构和功能的完整性、综合性等原则.

总之, 以上设想是基于目前对中国湖泊的分布状况和富营养化效应的认知而提出的, 相信在这个思路 下, 通过综合分析候选指标的历史和现场数据, 完全可以得到适合于中国湖泊营养盐分区的指标体系, 甚至 营养盐基准.

致谢: 感谢王洪铸研究员、周义勇研究员、王海军博士、席北斗研究员、高如泰研究员在指标体系构建方面的 建议!

\section{8 参考文献}

[ 1 ] Omernik JM. Map supplement ecoregions of the conterminous United States annals of the association of American. Geographers, 1987, 77 (1) : 118-125.

[ 2 ] Davies PE. Development of a national river bioassessment system, AUSRIVAS in Australia. In: Wright JF, Sutcliffe DW, Furse MT, eds. Assessing the biological quality of fresh waters-RIVPACS and other techniques. Ambleside: Freshwater Biology Association, 2000: 113-1241.

[ 3 ] Hemsley FB. Classification of the biological quality of rivers in England and Wales. In: Wright JF, Sutcliffe DW, Furse MT, eds. Assessing the biological quality of freshwaters-RIVPACS and other techniques. Ambleside: Freshwater Biology Association, 2000: 55-691.

[ 4 ] Austrian Standards. NORM M 62321 Guidelines for the ecological survey and evaluation of flowing surfacewaters. Vienna: Austrian Standards Institute, 1997: 381.

[ 5 ] Moog O, Schmidt-Kloiber A, Ofenböck T et al. Does the ecoregion approach support the typological demands of the EU Water Frame Directive? Hydrobiologia, 2004, 516 : 21-331.

[6] 周保华, 潘恒健, 谷长强. 湖泊水库营养状态分区研究进展. 环境与可持续发展, 2006, (3): 10-13.

[ 7 ] 孟 伟, 张 远, 郑丙辉. 水生态区划方法及其在中国的应用前景. 水科学进展, 2007, 18(2) : 293-310.

[8] 黄秉维. 中国综合自然区划的初步草案. 科学通报, 1959, 18(4) : 594-602.

[9] 窦鸿身, 王苏民, 姜加虎等. 中国湖泊综合分类原则、级别划分及分类程序之初探. 湖泊科学, 1996, 8(2): 173-178

[10］曾祥琮. 中国内陆水域渔业区划. 杭州：浙江科学技术出版社，1990.

[11] 李思忠. 中国淡水鱼类的分布区划. 北京: 科学出版社, 1981.

[12] 尹 民, 杨志峰, 崔保山. 中国河流生态水文分区初探. 环境科学学报, 2005, 25(4) : 423-428.

[13] 富 国. 湖泊富营养化敏感分级概念及指标体系研究. 环境科学研究, 2005, 18 (6) : 75-79.

[14] 孟 伟, 张 远, 郑丙辉. 辽河流域水生态分区研究. 环境科学学报, 2007, 27(6): 911-918.

[15］杨爱民, 唐克旺, 王 浩等. 中国生态水文分区. 水利学报, 2008, 39(3) : 332-338.

[16］孙小银, 周启星. 中国水生态分区初探. 环境科学学报, 2010, 30(2)：415-423.

[17] Bailey RG. Identifying ecoregion boundaries. Environmental Management, 2005, 34 ( Suppl) : S14-S26.

[18] Noss RF. Indicators for monitoring biodiversity: a hierarchical approach. Conservation Biology, 1990, 4: 355-364.

[19] Odum EP. Basic ecology. Philadelphia: Sounders College Publishing, 1983: 1-613.

[20] McMahon G, Wiken EDB, Gauthier DA. Toward a scientifically rigorous basis for developing mapped ecological regions. Environmental Management, 2004, 34( Suppl 1) : 111-124.

[21] Omernik JM. Ecoregions: A spatial framework for environmental management. In: Davis WS, Simon TP, eds. Biological assessment and criteria: Tools for water resource planning and decision-making. Florida: Lewis Publishers Boca Raton, 1995.

[22] McMahon G, Gregonis S, Waltman S et al. Developing a spatial framework of common ecological regions for the conterminous United States. Environmental Management, 2001, 28: 293-316.

[23] Loveland TR, Merchant JM. Ecoregions and ecoregionalization: geographical and ecological perspectives. Environmental Management, 2004, 34(Suppl 1) : 1-13.

[24] 孟 伟, 张 远, 郑丙辉. 水环境质量基准、标准与流域水污染物总量控制策略. 环境科学研究, 2006, 19(3): $1-6$.

[25] Omernik JM, Bailey RG. Distinguishing between watersheds and ecoregions. Journal of the American Water Resources Association, 1997, 33: 935-949.

[26] Bryce SA, Omernik JM, Larsen DP. Ecoregions: A geographic framework to guide risk characterization and ecosystem management. Environmental Practice, 1999, (1): 141-155.

[27] Péru N, Dolédec S. From compositional to functional biodiversity metrics in bioassessment: A case study using stream 
macroinvertebrate communities. Ecological Indicators, 2010, 10:1025-1036.

[28 ] Kay JJ, Schneider E. Embracing complexity: The challenge of the ecosystem approach. Alternatives, 1994, 20 : 33-39.

[29] Ives AR, Carpenter SR. Stability and diversity of ecosystem. Science, 2007, 317: 58-62.

[30] Stevenson RJ, Hill BH, Herlihy AT et al. Algae-P relationships, thresholds, and frequency distributions guide nutrient criterion development. Journal of the North American Benthological Society, 2008, 27(3) : 783-799.

[31] Handcock RN, Csillag F. Ecoregionalization assessment: Spatio-temporal analysis of net primary production across Ontario. Ecoscience, 2002, 9(2): 219-230.

[32] Handcock RN, Csillag F. Spatio-temporal analysis using a multiscale hierarchical ecoregionalization. Photogrammetric Engineering and Remote Sensing, 2004, 70(1): 101-110.

[33] 李 博, 雍世鹏, 曾泗弟等. 生态分区的原则、方法与应用一一蒙古自治区生态分区图说明. 植物生态学与地 植物学学报, $1990, \mathbf{1 4}(1)$ : 55-62.

[34] Dodds WK, Carney E, Angelo RT et al. Determining ecoregional and reference conditions for nutrients, secchi depth and chlorophyll a in Kansas lakes and reservoirs. Lake and Reservoir Management, 2006, 22(2) : 151-159.

[35] Pan BZ, Wang HJ, Liang XM et al. Factors influencing chlorophyll a concentration in the Yangtze-connected lakes. Fresenius Environmental Bulletin, 2009, 18(10): 1894-1900.

[36] Hou GX, Song LR, Liu JT et al. Modeling of cyanobacterial blooms in hypereutrophic Lake Dianchi, China. Journal of Freshwater Ecology, 2004, 19(4): 623-629.

[37] Bailey RG. Ecosystem geography. New York: Springer, 1996: 204.

[38] Tonn WM. Climate change and fish communities: a conceptual framework. Transactions of the American Fisheries Society, $1990, \mathbf{1 1 9}(2)$ : 337-352.

[39] 丁四保, 王 昱. 区域生态补偿的基础理论与实践问题研究. 北京: 科学出版社, 2010: 65 .

[40] Rosenberg D, Resh V. Freshwater biomonitoring and benthic macroinverteb rates. New York: Chapman and Hall, 1993.

[41] Resh VH, Kobzina NG. A perspective on the key citations in freshwater benthic science, and the studies that influenced them. Journal of the North American Benthological Society, 2003, 22(3) : 341-351.

[42] Scheffer M, Van Nes EH. Shallow lakes theory revisited: various alternative regimes driven by climate, nutrients, depth and lake size. Hydrobiologia, 2007, 584: 455-466.

[43] Justus B. Water quality of least-impaired lakes in eastern and southern Arkansas. Environmental Monitoring and Assessment, 2010, 68: 363-383.

[44] Ludovisi A, Poletti A. Use of thermodynamic indices as ecological indicators of the development state of lake ecosystems: 2. Exergy and specific exergy indices. Ecological Modelling, 2003, 159(2-3) : 223-238.

[45] Scheffer M, Carpenter S, Foley AF et al. Catastrophic shifts in ecosystems. Nature, 2001, 413: 591-596.

[46] Wang YC, Wang ZC, Wu WJ et al. Seasonal regime shift of an alternative-state Lake Xingyun, China. Fresenius Environmental Bulletin, 2010, 19(8): 1474-1485.

[47] Scheffer M, Szabo S, Gragnani A et al. Floating plant dominance as a stable state. Proceedings of the National Academy of Sciences of the United States of America, 2003, 100: 4040-4045.

[48] Dodds WK, Cole JJ. Expanding the concept of trophic state in aquatic ecosystems: It's not just the autotrophs. Aquatic Sciences-Research Across Boundaries, 2007, 69: 427-439.

[49] Reinds GJ, Posch M, De Vries W et al. Critical loads of sulphur and nitrogen for terrestrial ecosystems in Europe and Northern Asia using different soil chemical criteria. Water Air and Soil Pollution, 2008,193(1-4) : 269-287.

[50] Freeman AM, Lamon EC, Stow CA. Nutrient criteria for lakes, ponds, and reservoirs: A Bayesian TREED model approach. Ecological Modelling, 2009, 220(5) : 630-639.

[51] Salm CR, Saros JE, Fritz SC et al. Phytoplankton productivity across prairie saline lakes of the Great Plains (USA) : a step toward deciphering patterns through lake classification models. Canadian Journal of Fisheries and Aquatic Sciences, 2009, 66(9) : 1435-1448.

[52] Chang FY, Pan XJ, Kang LJ et al. Phosphorus bioavailability in relation to submerged macrophyte species and biomass in fourteen temperate lakes, China. Fresenius Environmental Bulletin, 2010, 19(1) : 50-56.

[53] Chang FY, Pan XJ, Li YH et al. Contamination assessment and potential mobility of sediment phosphorus from Dianchi Lake, China. Fresenius Environmental Bulletin, 2010, 19(1): 42-49.

[54] King RS, Richardson CJ. Integrating bioassessment and ecological risk assessment: An approach to developing numerical water-quality criteria. Environmental Management, 2003, 31(6) : 795-809.

[55] Kenney MA, Arhonditsis GB, Reiter LC et al. Using structural equation modeling and expert elicitation to select nutrient criteria variables for south-central Florida lakes. Lake and Reservoir Management, 2009, 25(2) : 119-130.

[56] Royer TV, David MB, Gentry LE et al. Assessment of chlorophyll-a as a criterion for establishing nutrient standards in the streams and rivers of Illinois. Journal of Environmental Quality, 2008, 37(2) : 437-447.

[57] Cao XY, Song CL, Zhou YY. Limitations of using extracellular alkaline phosphatase activities as a general indicator for describing P deficiency of phytoplankton in Chinese shallow lakes. Journal of Applied Phycology, 2010, 22 : 33-41. 